\title{
Has the Marital Time Cost of Parenting Changed Over Time?
}

Jeffrey P. Dew

Brigham Young University - Provo, jeff_dew@byu.edu

Follow this and additional works at: https://scholarsarchive.byu.edu/facpub

Part of the Other Social and Behavioral Sciences Commons

\section{Original Publication Citation}

Dew, J. P. (2009). Has the marital time cost of parenting changed over time? Social Forces, 88, 519-541.

\section{BYU ScholarsArchive Citation}

Dew, Jeffrey P., "Has the Marital Time Cost of Parenting Changed Over Time?" (2009). Faculty Publications. 4512.

https://scholarsarchive.byu.edu/facpub/4512 


\title{
Has the Marital Time Cost of Parenting Changed Over Time?
}

\author{
Jeffrey Dew, University of Virginia
}

Qualitative and quantitative research has suggested that married couples handle the increasing demands of intensive parenting norms and work expectations by reducing spousal time (e.g., the time that spouses spend alone with each other). Using nationally representative time-diary data, this study examined whether married individuals with children at home lost more spousal time in the years 1975-2003 than individuals without children at home. The analyses showed that on average married individuals have reduced their spousal time by 50 minutes a day. Contrary to expectations, however, individuals with minor children at home had lower time declines than individuals without children. The strategies that assisted married individuals with children to protect their spousal time differed between weekdays and weekend days.

Though it has rewards, contemporary parenting is an extremely demanding task. Parents expect more of themselves now than in the past as they strive to prepare their children to live in an increasingly complex world. Indeed, contemporary parents, especially middle- and upper-class parents, are investing more time, emotional effort and financial resources in their children than ever before (Lareau 2002; Stearns 2003; Zelizer 1994). And although married couples have increased the amount of time they spend in the paid labor force-mostly due to married women's increased labor force participation (Amato et al. 2007; Jacobs and Gerson 2004) - they spend at least as much time with their children now as in the past (Bianchi, Robinson and Milkie 2006; Sandberg and Hofferth 2001; Sayer, Bianchi and Robinson 2004). Researchers have suggested that one of the ways married parents have been able to parent intensively and increase their paid labor force participation is to decrease their spousal time-the time they spend alone with their spouses (Bianchi et al. 2006). Although intensive parenting norms may have decreased spousal time, research has not compared the spousal time changes of married individuals who have children at home with married individuals who do not have children at home. Thus, the spousal time cost exacted by the rise of intensive parenting remains unknown.

Evaluating spousal time changes vis-à-vis parenting shows how the intensive parenting norm is changing family relations. That is, the intensive parenting norm may be changing family behavior more than simply influencing parentchild behavior. For example, if spouses with children have decreased spousal time

I would like to gratefully acknowledge David Almeida, Alan Booth, Chalandra Bryant, David Eggebeen, Geoff Godbey, Jennifer Hook, Steve Nock and Brad Wilcox for their helpful comments on previous drafts. A grant from the Social Trends Institute supported the author's efforts in this research. Direct correspondence to Jeffrey Dew, Department of Sociology, University of Virginia, 542 Cabell Hall, P.O. Box 400766, Charlottesville,VA 22904-4766. E-mail: jpd197@juno.com. 
more than spouses without children then that would indicate that the intensive parenting norm has become stronger than norms governing spousal interaction. Ironically, the link between spousal time declines and the presence of children also has important implications for child wellbeing; the quality of a couple's marriage relates to the quality of their parenting (Coiro and Emery 1998; Erel and Burman 1995). Although research has linked spousal time declines to parenting obligations, the counter-factual (e.g., that spousal time declines for couples without children have also occurred) has never been evaluated. By analyzing spousal time changes for couples with children at home and couples without children at home this study assesses whether intensive parenting has changed spousal time.

Using nationally representative time-diary data, this study analyzed spousal time changes over the past 30 years. The multivariate analyses assessed overall changes in spousal time. They also compared spousal time trends among married couples with children with the trends of married couples without children. Finally, this study also examined the time-allocation and population-change mechanisms behind the trends.

\section{Intensive Parenting and Spousal Time}

\section{The Intensive Parenting Norm}

Contemporary parenting has become an extraordinary time commitment. As Americans have increasingly delayed childbirth (Bachu and O'Connell 2000; Bumpass 1982; Ventura et al. 2004), parents have expected to invest more in their children now than in the past. For example, the norm of motherhood asserts that children need extensive maternal nurturing and guidance (Hays 1996). Although the norm of motherhood has existed since the $19^{\text {th }}$ century, it changed in the early to mid $20^{\text {th }}$ century. As birth rates continued to decline and children became more emotionally and socially valuable, the norm of motherhood began to assert that children were vulnerable entities who required substantially higher maternal inputs than in the past (Stearns 2003; Zelizer 1994).

Fathers have also increasingly felt the intensive parenting norm. At the beginning of the $20^{\text {th }}$ century, many individuals began to assert that fathers needed to spend more time parenting (Griswold 1997). While the ways in which men were to interact with and socialize their children changed over the $20^{\text {th }}$ century, the call for more paternal involvement was constant (Griswold 1997; Pleck and Pleck 1996; Stearns 2003). Evidence that men are aware of this norm is found in the fact that more fathers than mothers report feeling that they do not spend enough time with their children (Jacobs and Gerson 2004; Milkie et al. 2004). If men were not aware of the norm of intensive parenting, they would not report spending too little time parenting.

Parents have responded to the intensive parenting norm. Contemporary parents feel more pressure now than in the past to spend their time directly engaged with their children (Coltrane 1996; Stearns 2003). Moreover, children have first claim on 
their parents' non-working time (Daly 2001; Simon 1995). Further, many parents feel that they spend insufficient time with their children (Jacobs and Gerson 2004; Milkie et al. 2004). In short, parents feel intensely obligated to spend as much time with their children as possible. Because they do not live up to their own ideals they feel "...guilt for working too much, guilt for not spending enough time with their children, guilt for getting babysitters, guilt when they [want] their children to go to bed, and guilt for taking time for themselves."(Daly 2001:292)

Perhaps parents should feel less guilt. In terms of time spent parenting, mothers spend about the same time with their children now as mothers in the past, and some research has suggested that mother-child time has increased (Bianchi et al. 2006; Sayer et al. 2004; Sandberg and Hofferth 2001). Fathers have also increased the amount of time they spend with their children (Bianchi et al. 2006; Sandberg and Hofferth 2001; Sayer 2005; Sayer et al. 2004).

\section{Parenting and Spousal Time}

Some research has suggested that married parents have cut back on time with their spouses to be with their children. Qualitative studies have focused on the obligation parents feel to provide parent-child time (Daly 2001; Hays 1996). Parents have reported feeling deeply obligated to provide their children with time, attention and opportunities that will give their children good memories of their childhood and help prepare them for life (Daly 2001; Lareau 2002). To give them this time, parents cut back on their own activities (Bianchi 2000).

Not surprisingly, these studies have also noted the relationship between intensive parenting and spousal interaction. For example, in a study of gender roles one wife noted, "At this time in my life being a mother is number one and being a wife is number two... I think that causes problems... It's easier for me to say no to something he wants than it is for me to say no to something the kids want."(Simon 1995:188) A participant in a study of family time "...was resigned to making family time a priority over their time as a couple when she indicated that it is 'something that we will get in the future and for now we'll just make the best with what we have."'(Daly 2001:291)

Quantitative studies have begun to corroborate qualitative findings on the link between intensive parenting and spousal time. For example, Bianchi et al. (2006) found that the total time that married parents' spent with each other declined by three hours per week from 1975 through 2000. Other studies that have used stylized questions rather than time-diary data have also found spousal interaction declines (Amato et al. 2007). Based on these studies of the strength of the intensive parenting norm, I expect that couples with children at home ${ }^{1}$ will have lost more spousal time than couples without children at home. 


\section{Contextual Considerations}

Individuals allocate time to activities beyond spending time with their spouses and parenting. Some of these activities, such as paid employment, often leave less time for family activities. The amount of paid employment that a spouse works is likely related to his or her spousal time simply because the more time that a spouse spends in paid employment the less time they have to spend with their spouses. Further, the type of earning arrangement that a couple has also predicts spousal time. Time-diary data has shown that dual-earning couples spend less time together than single-earning couples (Kingston and Nock 1987). Finally if spouses work irregular schedules, they may have less spousal time because when one spouse arrives home, the other spouse may be heading to work (Kingston and Nock 1987; Presser 2000).

Age may also predict spousal time. Older individuals have been married longer, on average, and thus are a select group because many of their peers have divorced. With higher marital quality, on average, these couples would likely spend more time together (White 1983). Further, although this study contains only couples in which at least one partner is working, older individuals may also have less of a financial need to work long hours.

Race and ethnicity may also predict spousal time. Racial and ethnic minority families are often more oriented to the collective good of their families than majority couples. For example, in a qualitative study black newlyweds were more likely to talk about their relationships and marital goals whereas European-American couples were more likely to discuss their personal career goals (Chadiha, Veroff and Leber 1998). Thus, race/ethnic minority spouses might value spousal time more and strive to spend more time alone together.

Class differences in intensive parenting and spousal time may occur, necessitating controls for income and education. The vulnerable children/intensive parenting norm originated in the middle class (Stearns 2003; Zelizer 1994). Further, the meaning of parent-child time differs across social class lines. Many middle-class parents spend a lot of time parenting by selecting, coordinating and ferrying their children to structured leisure activities such as music lessons, sports teams and artistic endeavors to enhance their children's growth and advancement (Lareau 2002). Middle-class parents also spend more time talking with their children and monitoring their children's lives (Lareau 2002). By way of contrast, working class and poor parents allow children to "naturally develop" and do not structure family time as much as middle-class parents do. If these differences in parental time investments generalize to national samples, then middle-class parents may have less spousal time.

Finally, spousal time estimates may differ by gender. Husbands experience more leisure time at home than wives (Larson and Richards 1994; Sayer 2005). Men are also more likely than women to report wanting to spend more time with 
family members (Roxburgh 2006). These two factors may lead husbands to be more sensitive to when they are with their wives or to simply overreport the time spent with their wives.

\section{Method}

\section{Data and Sample}

The data for this study came from two nationally representative time-use surveys, the Time Use in Economic and Social Accounts 1975-1976, and the American Time Use Survey 2003. ${ }^{2,3}$ The TUESA was conducted by the Institute for Social Research at the University of Michigan (Juster et al. 2001). The survey relied on a national probability sampling framework. First, the researchers randomly sampled individual households from primary sampling units. They then visited the participants and helped them fill out a time diary. To generate time-diary data, participants chronologically listed the beginning and ending times of the activities they undertook the previous day. They also reported who was with them during each activity. The sample is nationally representative of the continental U.S. population in 1975.

The ATUS 2003 is the first time-use study conducted by the Bureau of Labor Statistics. It utilized a subsample of the Current Population Survey and oversampled race and ethnic minority groups. In 2003, the first ATUS was given to a subsample of CPS participants who had completed their eight-month rotation in the CPS. Like the TUESA, the ATUS 2003 asked respondents to produce a time diary on the previous day's activities.

Time-diary methodology offers advantages over traditional survey questions about marital interactions. First, time diaries explicitly tie data to "clock" time so they offer precise estimates of time use. Second, research has shown that time-diary methods produce better estimates of time in non-work activities than stylized questions that differ from survey to survey (Juster and Stafford 1985; Robinson and Godbey 1999). Third, time-diary methods reduce participants' tendency to give socially desirable answers as it is difficult to create a coherent fabrication when it is situated in a chronological report of other activities (Robinson and Godbey 1999; Stinson 1999). Finally, time-diary methods are geared toward knowing who the participant was with during each activity. This feature facilitates estimating spousal time.

For the purposes of this study, participants in the TUESA 1975 and the 2003 ATUS were included if they were married ${ }^{4}$ and at least one of the spouses was employed. These selection criteria yielded a total sample of 9,674 participants -818 participants from the 1975 study and 8,856 participants from the 2003 ATUS. Although age was not an inclusion criterion, the requirement that at least one spouse be working meant that the participants' average age was in the mid- 40 s with 95 percent of the participants ages 18-64.

Because participants had considerably more spousal time on weekend days, analyses for weekdays and weekend days were conducted separately. That is, if a 


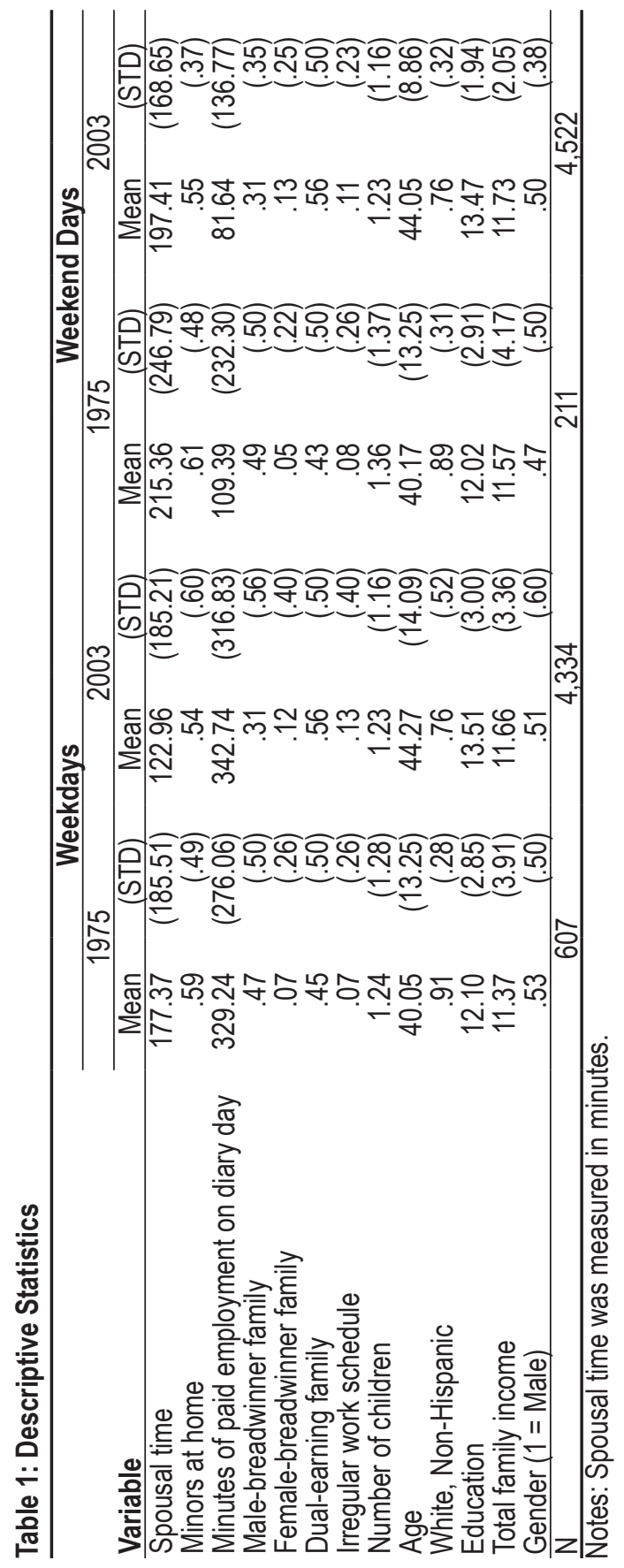


participant reported time use on Monday through Friday they were put into the weekday sample. If they reported time use on Saturday or Sunday, they were put into the weekend sample. Thus, the descriptive results in Table 1 were reported separately by year and by whether a participant reported about a weekday or a weekend day.

\section{Measures}

\section{Spousal Time}

Spousal time was the dependent variable and was reported in minutes. Spousal time was a measure of the total time during the diary day that spouses were alone together. Regardless of the activity they were engaged in, if spouses were with each other and no one else was present this time segment was included in their spousal time measure.

\section{Parenting and Work Variables}

The key independent variables were parenting variables. One variable was a dichotomous variable that indicated whether the couple had any minor children living at home ( $1=$ Children in the home). The second variable indicated how many children were in the home. These variables were derived from information on the household roster.

Four variables measured employment behavior. The first variable was the number of minutes that participants spent in paid employment on the diary day. ${ }^{5}$ The second and third employment variables were categorical variables that indicated whether the couple was in a husband-single-earner or wife-single-earner arrangement (dual earners were the omitted category). These variables were created by using the participants' reports of who was employed in the household. The last employment variable was also categorical and measured whether the participant had irregular employment hours. If employment began before 6 a.m. or after 3 p.m. they were coded as having an irregular work schedule.

\section{Other Variables}

A dummy variable captured the main effect for year of the time-use survey $(1=$ 2003). The analyses also included age, race, gender, education and total family income as control covariates in all of the analyses. Age was reported by the participants and measured in years. Race was a dichotomous variable. If participants categorized themselves as White, Non-Hispanic they received a 1 . The omitted category was composed of participants who classified themselves as race/ethnic minorities. Gender was also a dichotomous variable $(1=$ Male). Education measured the number of years of education the respondent had completed.

Both surveys measured income using a range of values, rather than exact dollar amounts. For example, a participant could state that his or her household income was $\$ 25,000-\$ 29,999$. Researchers then coded these ranges into a numerical scale. For example, if in 2003, a participant's total family income was $\$ 25,000-\$ 29,999$ 
he or she received an " 8 " on the scale. Although the scale amounts differed in 1975 and 2003, they were comparable in a relative sense. ${ }^{6}$

Descriptive statistics for the variables in 1975 and 2003 are found in Table 1. Because a few of the subjects were missing data on income, age or education, multiple imputation techniques were used to generate plausible values for participants with missing values in these variables.

\section{Analyses}

The first analyses were OLS regressions. Spousal time was regressed onto the year dummy variable, the parenting variables, the work variables and the control variables for both the weekday and weekend day sample. To explain spousal time changes I also analyzed other variables (such as minutes of work on the diary day) by regressing these variables on the year, parenthood, year by parenthood interaction and control variables. All of the regressions used the population weights provided in the datasets.

After the OLS regressions were run, average predicted minutes of spousal time were graphed. This was accomplished by entering the year and parenthood variable values into the regression equation, and by holding the other statistically significant variables at their mean. I used overall sample means to generate the predicted values rather than using the 1975 and 2003 means, because doing so might lead to trend distortions due to changes in the population over time.

But because changes in the characteristics of the U.S. population might explain changing spousal trends, it was also important to assess how they related to the spousal time trends. That is, although time-allocation changes "explain" the aggregate spousal time trends, ${ }^{7}$ population shifts might help explain the time allocation shifts. For example, having more dual-earner couples in 2003 might explain increases in employment and declines in spousal time trends. Thus, I ran spousal time-trend decompositions. Trend decomposition helps clarify how social changes such as population shifts or behavioral changes relate to trends (Firebaugh 1997). Decomposition analyses have been used recently in studies of time-use trends (Amato, Johnson, Booth and Rogers 2003; Sandberg and Hofferth 2001). They are useful because often many different population changes are implicated in time-use trends.

Decomposition analyses partition change in the dependent variable into four parts-the contribution of intercept changes $(\Delta \alpha)$, the contribution of changes in the relationship between the dependent and independent variables holding the means at time 1 levels (e.g., changes in regression coefficients, $\sum_{x_{1}} \Delta b$ ), the contributions of changes in the means of the independent variables holding the regression coefficients at time 1 levels $\left(\sum \Delta \bar{x} b_{1}\right)$ and the joint contribution of changing means and regression coefficients changes $\left(\sum \Delta \bar{x} \Delta b\right)$ (Firebaugh 1997). Mathematically, the decomposition is expressed as:

$$
\bar{y}_{2}-\bar{y}_{1}=\Delta a+\sum \bar{x}_{1} \Delta b+\sum \Delta \bar{x} b_{1}+\sum \Delta \bar{x} \Delta b \text {. }
$$


To conduct the decomposition, two least squares regressions were run-one for the 1975 participants and one for the 2003 participants. The 1975 intercept was then subtracted from the 2003 intercept to get change in spousal time attributable to changes in the intercept $(\Delta \alpha)$. Next, each unstandardized coefficient from the 1975 regression was subtracted from the corresponding 2003 coefficient. When these changes were multiplied by the mean of the 1975 variable and then summed $\left(\sum \bar{x}_{1} \Delta b\right)$, this showed the contribution of changes in the relationship between spousal time and the independent variables.

Next, changes in the means of the independent variables over time were examined. Weighted 1975 means were subtracted from weighted 2003 means. These values were then multiplied by their corresponding 1975 regression coefficient and summed. This value was the change in spousal time that is related to changes in sample means over time $\left(\sum \Delta \bar{x} b_{l}\right)$. Finally, the change in means were multiplied by the changes in regression coefficients and summed to get the proportion of change in spousal time that is associated with the joint changes in means and regression coefficients $\left(\sum \Delta \bar{x} \Delta b\right)$.

\section{Results}

\section{Overall Spousal Time Trends}

Figure 1 shows the means of weekday and weekend ${ }^{8}$ day levels of spousal time in 1975 and 2003 based on the presence of children in the home. Although these mean differences do not take into account the employment and control variables, they provide a baseline against which to measure the multivariate models. Figure 1 demonstrates that most groups experienced spousal time decline. These declines ranged from 45 to 80 minutes, depending on the group. Finding overall spousal time declines was consistent with other studies (Amato et al. 2007; Bianchi et al. 2006). Further, Figure 1 also shows that married individuals with children at home reported much lower levels of spousal time than individuals without children. Couples with children at home reported between 116 and 290 fewer minutes of spousal time depending on the year and group.

Surprisingly, however, when the declines are compared across the groups Figure 1 indicates that couples with children at home had less of a decline. I expected that the declines would be greater for the children-at-home group because of the intensive nature of contemporary parenting. However, the couples with children at home had a decline that was 35 minutes lower on weekdays than couples without children. Further, on weekend days, couples without children reported a slight increase rather than a decline. This suggests an interaction that goes in the opposite direction than was hypothesized. 
Figure 1. Mean Changes in Spousal Time by Presence of Children

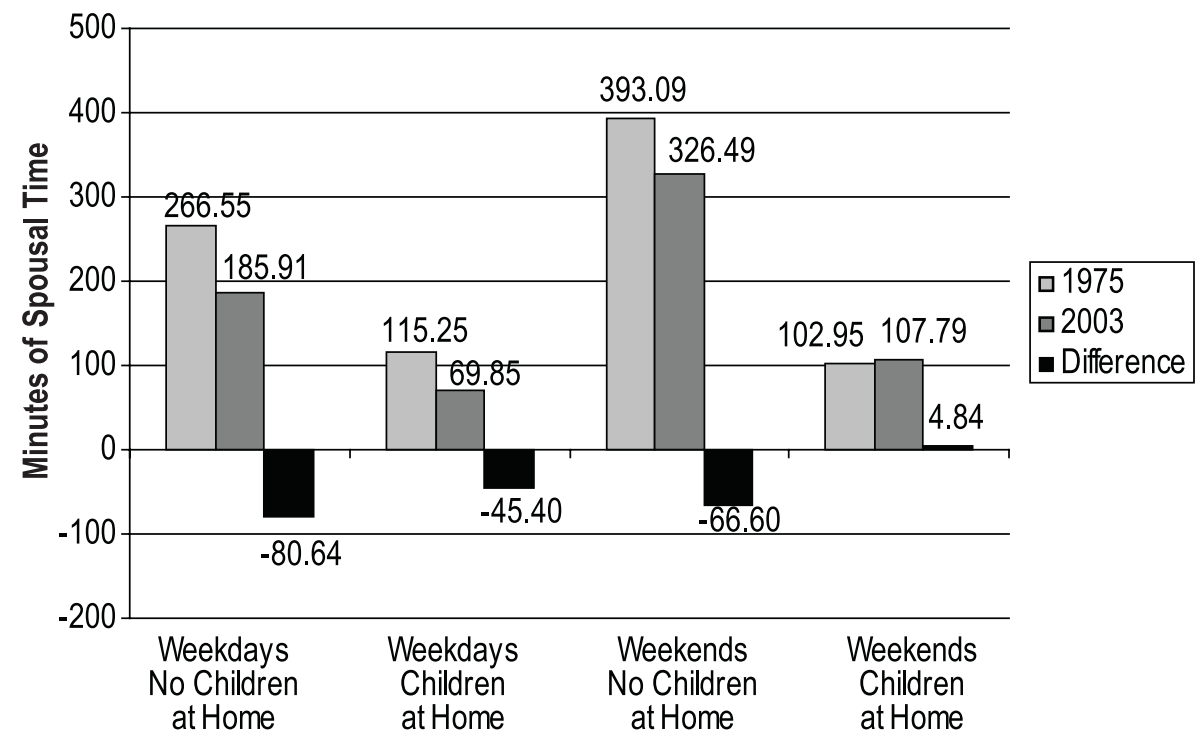

\section{Multivariate Models}

As expected, the OLS regression showed that having minor children at home was related to lower average spousal times. Even after controlling for other variables, having children at home was associated with 91 to 180 fewer minutes of spousal time depending on the diary day surveyed (see Table 2). Further, the main effect for year was statistically significant; the coefficients indicated a 38-59 minute decline from 1975 to 2003 after accounting for the control variables. Thus, as expected, having a child at home was associated with less spousal time and spousal time declines over time were evident.

However, examining the interaction term between having minor children at home and the year corroborated the surprising mean difference in Figure 1. That is, in the multivariate regressions the year by presence of child interaction was significant and showed that couples with children at home lost less time (see Table 2 and Figure 2). The predicted declines from the OLS regression were similar to the means; couples without children at home lost about 75 minutes of spousal time on both weekdays and weekend days. However, on weekdays, couples with children at home lost only 46 minutes and the spousal time decline for these couples was near zero on weekend days. ${ }^{9}$ These unexpected findings raised the question of how married couples with children at home were able to protect their 
spousal time. Put another way, what did the couples without children at home do with the time they had been spending together in 1975?

To answer this question, I first analyzed time devoted to paid employment on the diary day. To assess whether couples differed on the number of minutes in paid employment on the diary day, I regressed participants' time-diary minutes of paid employment on the year, parent variable, year by parent interaction and the control variables. The results showed that on weekdays a statistically significant child by year interaction emerged, but the main effects for year and having children at home were not significant (see Table 3). When the interaction was graphed, it was apparent that, on average, individuals without children at home in 2003 spent 26 minutes more per day in paid employment than their counterparts in 1975, while individuals with children at home in 2003 spent 21 minutes less per day in paid

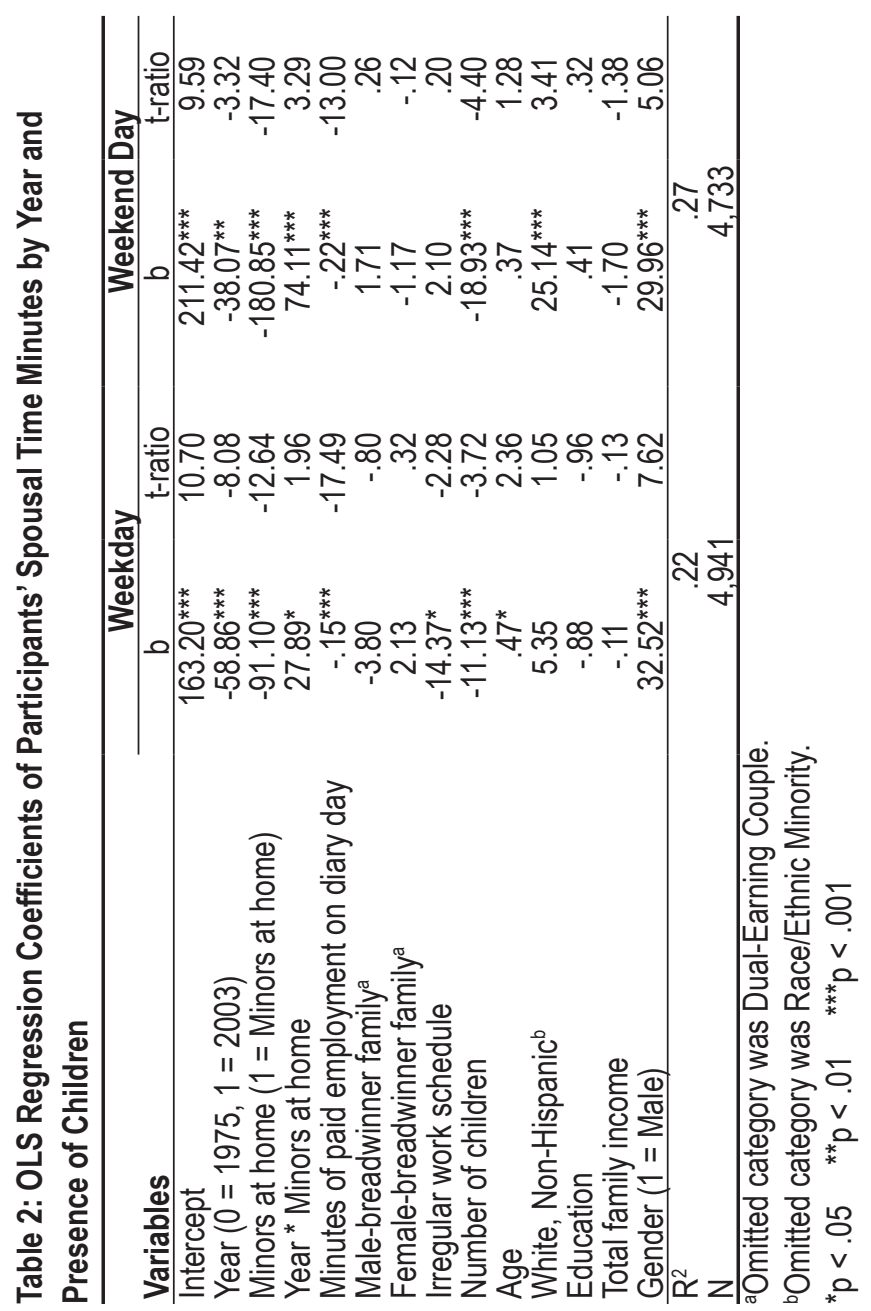


Figure 2. Predicted Declines in Spousal Time by the Presence of Children at Home

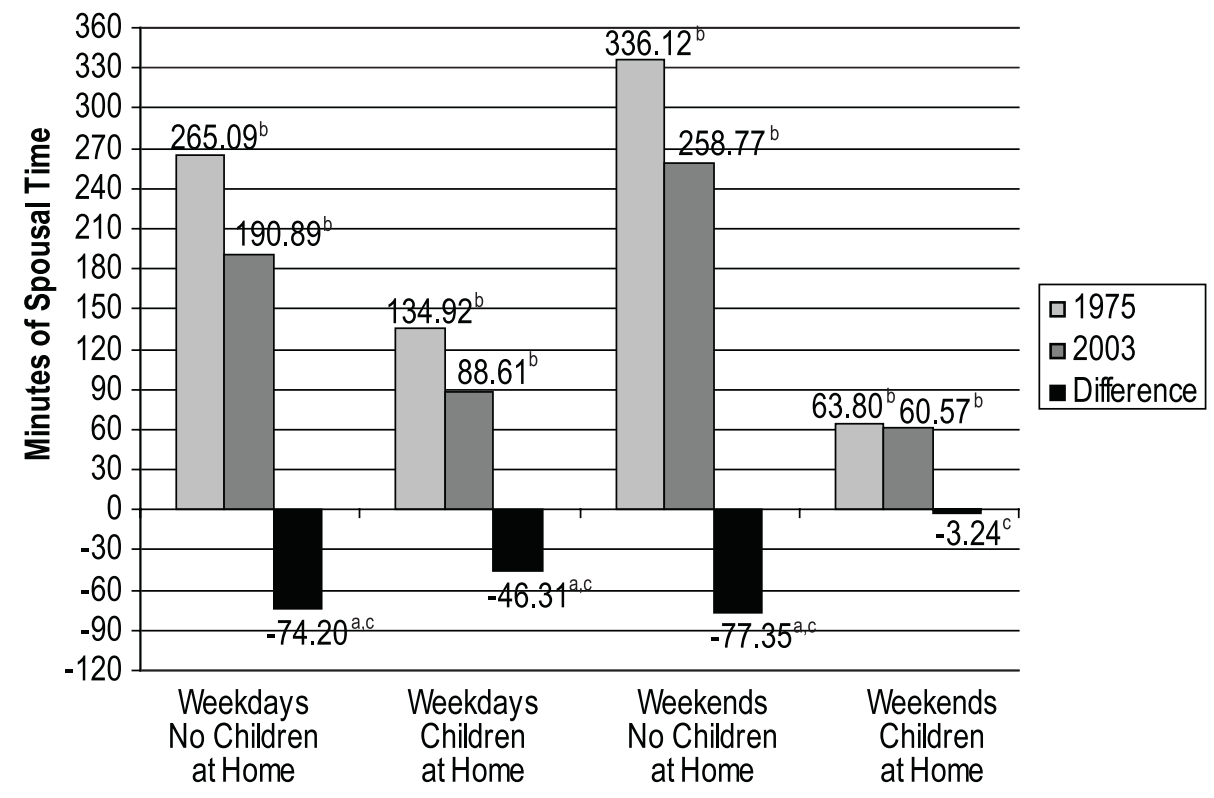

aDecline significant at the $p<.05$ level or better.

${ }^{b}$ Main effect for Children in the home significant at the $p<.05$ level or better.

'Decline by Children in the Home Interaction significant at the $p<.05$ level or better.

Table 3: Participants' Paid Employment Minutes on the Diary Day by Presence of Children

\begin{tabular}{|c|c|c|c|c|}
\hline \multirow[b]{2}{*}{ Variables } & \multicolumn{2}{|c|}{ Weekday } & \multicolumn{2}{|c|}{ Weekend Day } \\
\hline & $b$ & t-ratio & $\mathrm{b}$ & t-ratio \\
\hline Intercept & $270.67^{* * \star}$ & 10.99 & $119.20^{\star \star \star}$ & 6.32 \\
\hline Year & -13.27 & -1.11 & $-35.30^{* * *}$ & -3.59 \\
\hline Minors at home & -3.28 & -.28 & -11.62 & -.130 \\
\hline Year * Minors at home & $-48.08^{*}$ & -2.06 & 17.26 & .89 \\
\hline Male-breadwinner familya & $-151.11^{* * *}$ & -20.28 & $-16.15^{\star *}$ & -2.83 \\
\hline Female-breadwinner familya & $-148.23^{* * *}$ & -13.80 & $-20.31^{*}$ & -2.47 \\
\hline Irregular work schedule & $139.35^{* * *}$ & 13.73 & $219.40^{* * *}$ & 26.58 \\
\hline Number of children & -9.23 & -1.88 & 3.37 & .91 \\
\hline Age & $-1.63^{* * *}$ & -4.96 & -.22 & -.88 \\
\hline White, Non-Hispanic ${ }^{b}$ & -6.70 & -.81 & -10.24 & -.162 \\
\hline Education & $7.09^{* * *}$ & 4.74 & -1.68 & -1.51 \\
\hline Total family income & 2.57 & 1.86 & $-3.31^{* *}$ & -3.15 \\
\hline Gender (1 = Male) & $160.69^{* * *}$ & 24.27 & $47.81^{* * *}$ & 9.48 \\
\hline$\frac{\mathrm{R}^{2}}{2}$ & & & 4.7 & \\
\hline
\end{tabular}

amitted category was Dual-Earning Couple. ${ }^{b} O$ mitted category was Race/Ethnic Minority.

${ }^{*} p<.05 \quad{ }^{* *} p<.01 \quad{ }^{* * *} p<.001$ 
Figure 3. Predicted Changes in Time Spent in Paid Employment on Weekdays by Presence of Children

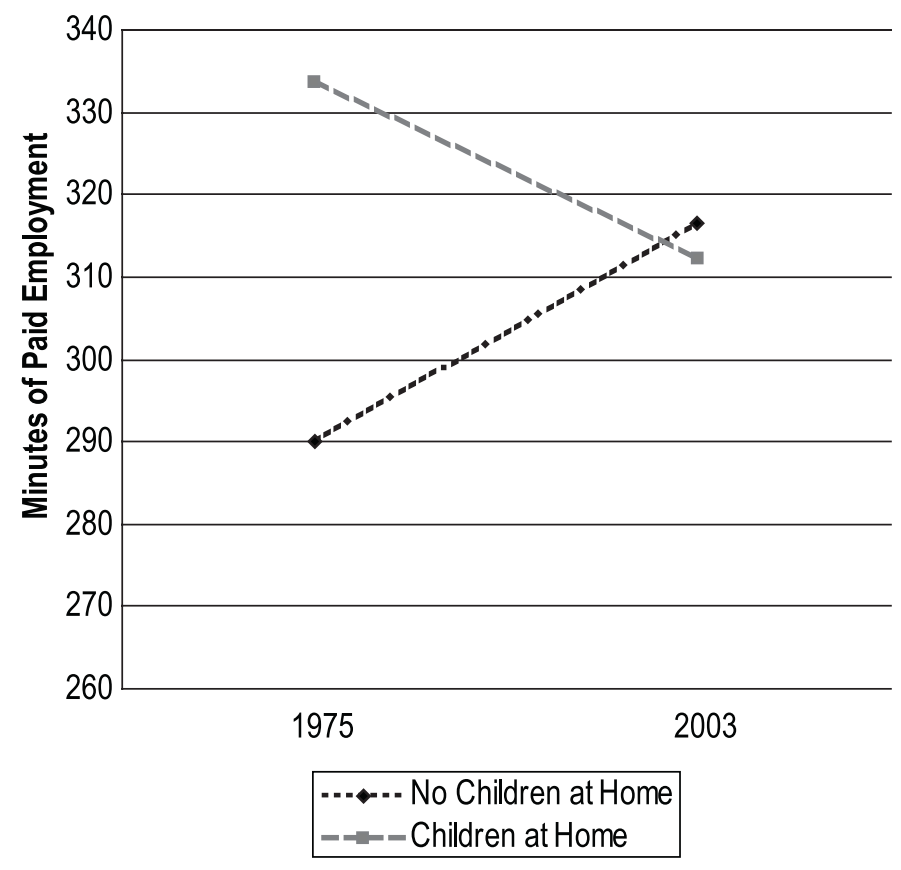

employment (see Figure 3). Consequently, individuals with children at home may have protected their spousal time on weekdays partly by engaging in paid employment less than they did in 1975, while individuals without children at home lost spousal time partly because they engaged in paid employment more than in 1975.

Because the year by minor at home interaction did not predict paid employment on weekend days, couples without children at home did not lose time on weekend days due to paid employment (Table 3). On average individuals (regardless of the presence of children) experienced a 35-minute drop in paid employment on weekends. An alternative possibility is that couples with children at home protected their weekend spousal time by cutting out spending time with other individuals. Recent research has shown that married individuals spend less time with friends and relatives than single and divorced individuals (Gerstel and Sarkisian 2006). Thus, to maintain spousal time on weekend days, couples with children at home may have reduced the amount of time they spent together, with relatives or friends, and spent this time alone with each other. Alternatively, couples with children at home may have protected their spousal time by foregoing personal leisure time. Studies of parent-child time have shown that employed mothers have protected the time they spend with their children by foregoing sleep and other personal time (Bianchi 2000).

Multivariate regression analyses of personal time spent with friends and family, and of leisure time spent alone, supported both these ideas. That is, a year 
Figure 4. Predicted Declines in Time Spent with Others and Solitary Leisure Time on Weekend Days by Presence of Children

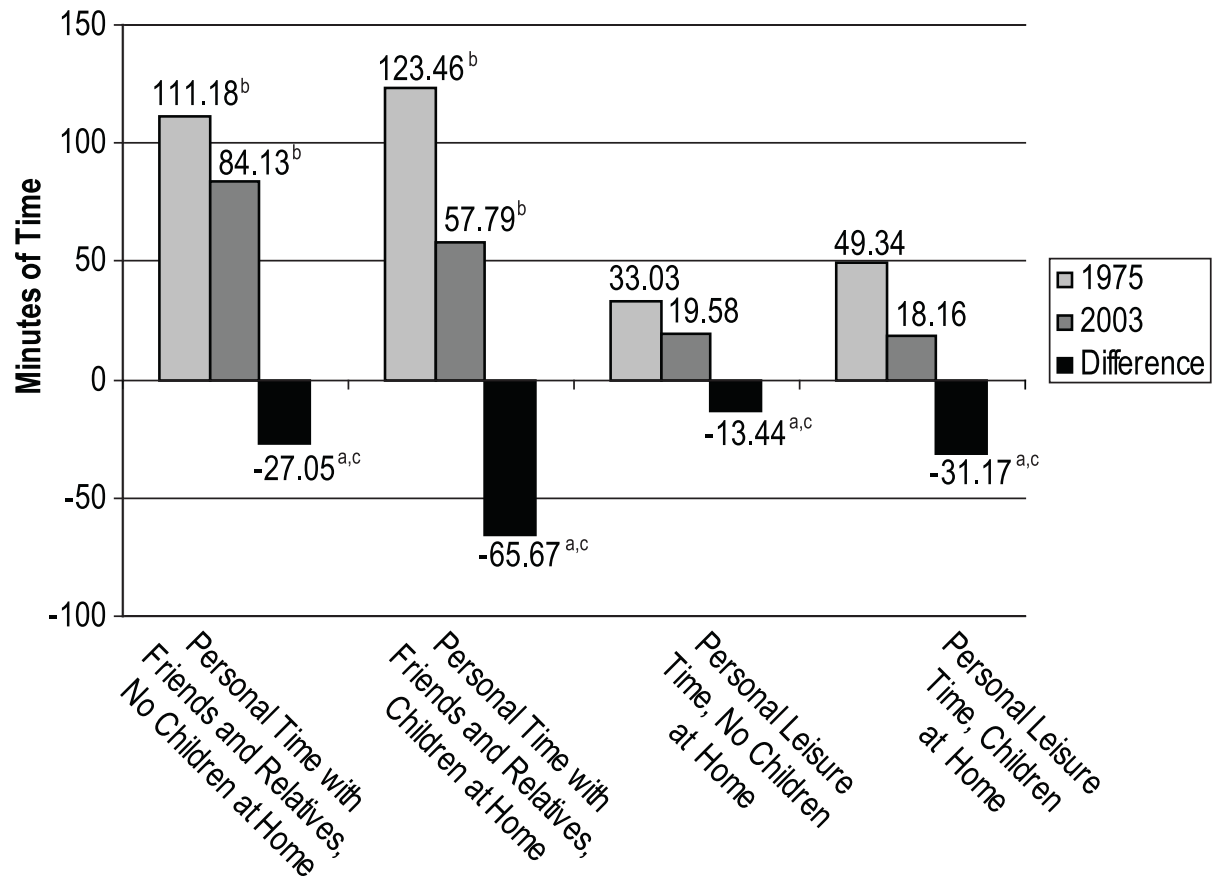

${ }^{a}$ Decline significant at the $p<.05$ level or better.

${ }^{b}$ Main effect for Children in the Home significant at the $p<.05$ level or better.

'Decline by Children in the Home Interaction significant at the $p<.05$ level or better.

by presence of children interaction was significant in both analyses (analysis not shown). Figure 4 graphed the interactions. Although the time that participants individually spent with their extended family and friends declined for both types of couples, couples with children at home had a more substantial decline. Thus, individuals with children at home partially protected their spousal time by forgoing personal time with friends and extended family. Additionally, individuals with children at home gave up more personal leisure time than individuals without children at home.

\section{Trend Decomposition}

Tables 4 and 5 show the results of the trend decomposition for weekdays and weekend days (respectively). Table 4 shows that on weekdays, the intercept decline component was greater than the actual mean decline in spousal time. Thus, the other components (change in coefficients, change in mean by change in interaction) exerted slight positive effects and balanced the equation. 


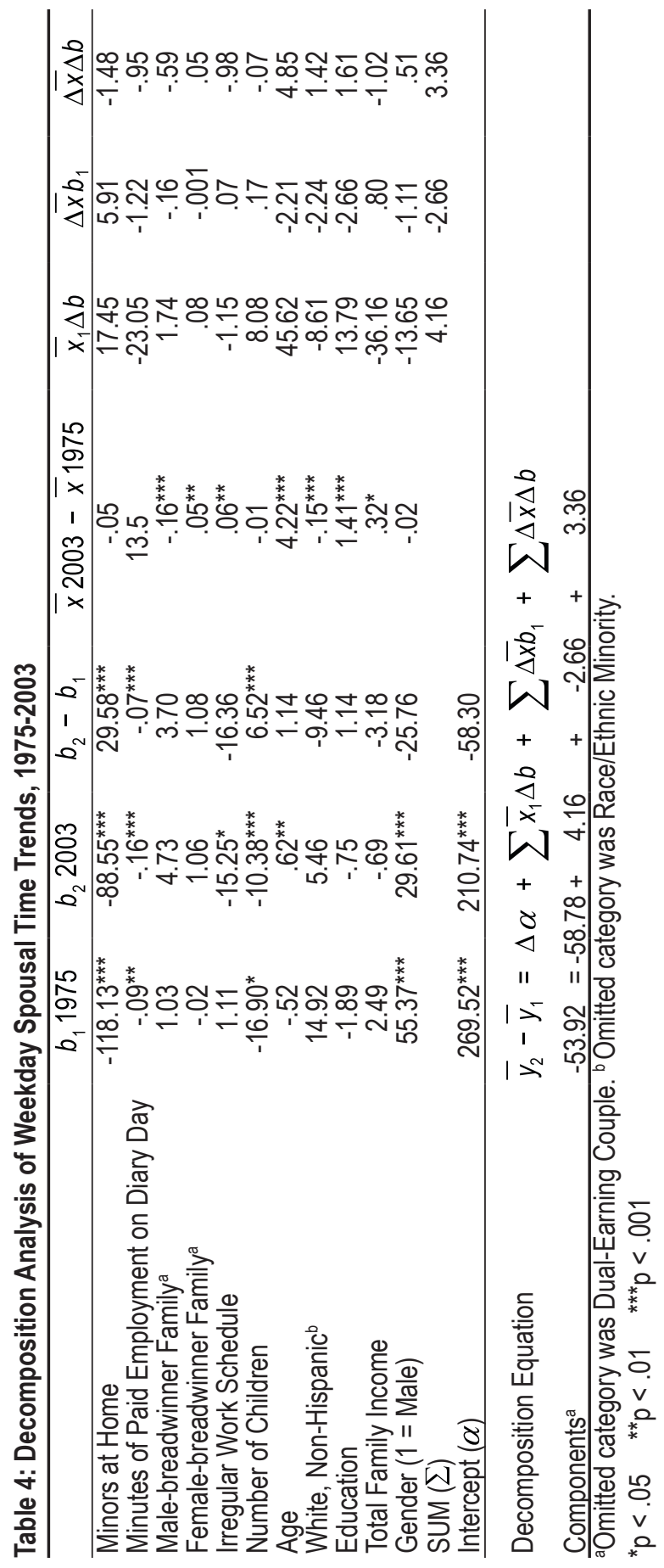




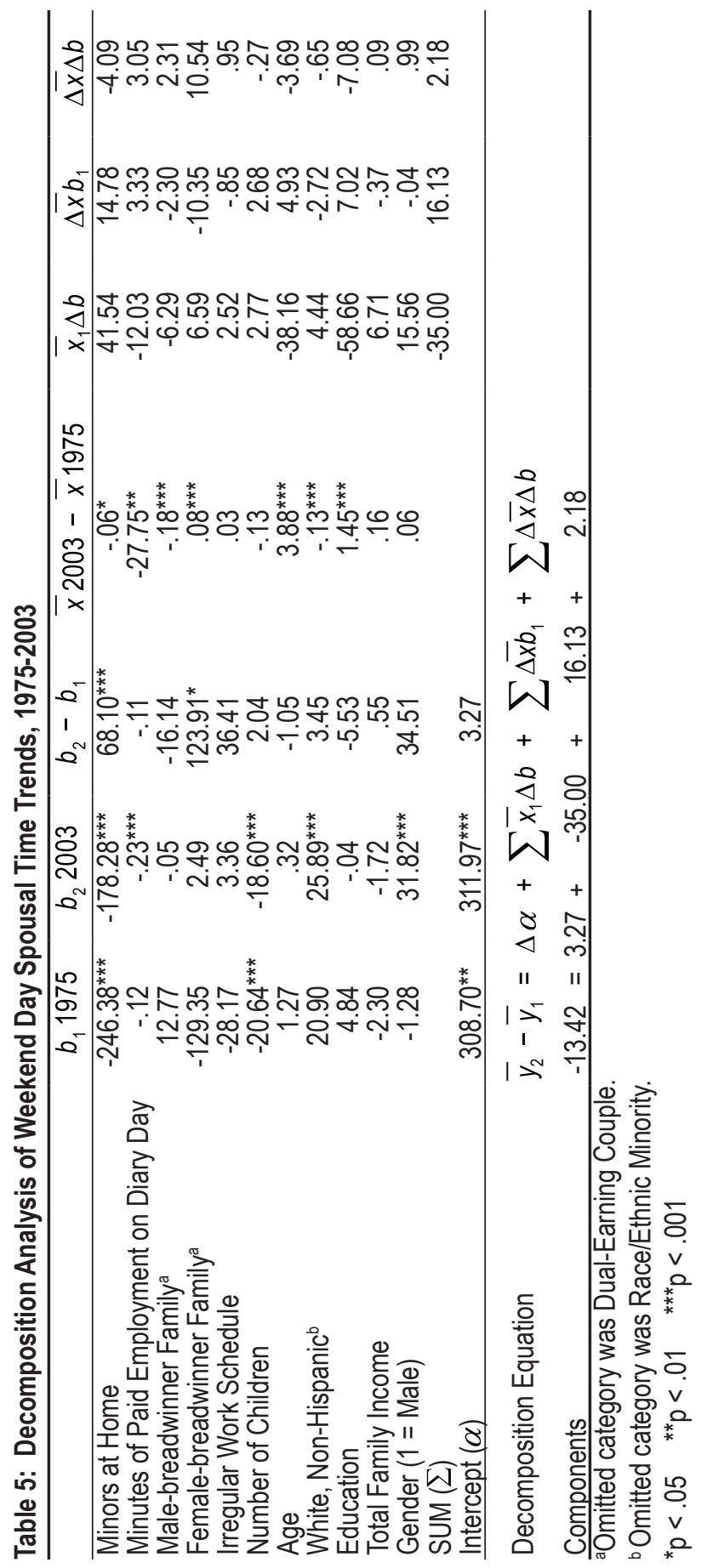


On weekdays, the only three coefficient changes that were significant in the coefficient change column $\left(b_{2}-b_{1}\right)$ were having children at home, minutes of paid employment and number of children. The coefficient changes for having children at home and for the number of children at home were both positive, indicating that having children at home became less of a drag on spousal time during our period of study. However, changes in the coefficients balanced each other out overall such that the sum of coefficient change column $\left(\sum_{x_{1}} \Delta b\right)$ was only 4.16 . Further, although most of the changes in the mean levels of the independent variables were significant, these changes cancelled each other out such that they did not contribute to the decomposition much. Thus, the weekday trend decomposition supports the same conclusion as the OLS analysis; changes in time allocation, not population changes, explain the spousal time changes.

The parenthood aspect of the weekend day decomposition (Table 5), yielded similar results. The coefficient for having minors at home was one of only two coefficients that significantly changed, and the change was positive. Further, the 6 percentage point decline in the number of couples with children at home was significant and was part of the positive mean-change component.

Interestingly, however, the rest of the weekend day decomposition was different from the weekday decomposition. The change in coefficients portion of the decomposition was negative, whereas the mean changes were positive. For example, the fact that the age coefficient declined so substantially was negative in the changing coefficient column, but the increase in the mean age exerted a small positive effect. Interpreting the components of the weekend day decomposition was difficult. For example, although changes in the age, education and family income coefficients yielded large coefficient change components $\left(\sum \bar{x}_{I} \Delta b\right)$ the actual coefficient changes for these variables were not significant. In the mean changes column $\left(\sum \Delta \bar{x} b_{l}\right)$, population aging and the increased number of female-breadwinning couples contributed somewhat to the overall total, but these changes largely offset each other. Thus, the results of the weekend day decomposition neither disprove nor strengthen the OLS findings on time allocation change.

\section{Discussion}

The purpose of this study was to evaluate whether couples with children at home resolve the tension between parenting norms and work expectations by reducing time alone with each other. It did this by comparing spousal time trends for married couples with children at home to the spousal time trends for married couples without children at home. Not surprisingly, the results showed that average spousal time declined by nearly an hour per day (see also Amato et al. 2007; Bianchi et al. 2006). However, married couples with children at home did not decrease spousal time more than couples without children at home. Rather, couples with children at home experienced smaller spousal time declines than those without children on weekdays, and on weekend days couples with children lost no spousal time. 
Because these findings were unexpected, this study also investigated the timeuse strategies that couples with children at home employed to maintain spousal time. The strategies differed on weekdays and weekend days. The weekday differences in spousal time loss seemed to stem from paid employment trends. From 1975 through 2003, participants without children at home increased their average minutes of paid employment by about 26 minutes, whereas the participants with children at home decreased the number of paid employment by about 21 minutes. This paid employment tradeoff more than accounts for the 35 minutes of extra time that couples without children lost. The trend decomposition further supported the idea that individuals' time allocation explained the decline.

This finding demonstrates that married couples with children at home responded to the intensive parenting norm not by cutting spousal time inordinately, but by decreasing paid employment involvement. Thus, married couples with children are behaving consistently with their stated desires. Many studies have shown that adults report wanting to spend more time with their families (e.g., Jacobs and Gerson 2004; Roxburgh 2006); married couples with children cut paid employment time to do that. Interestingly, couples without children at home increased the amount of weekday time spent in paid employment.

It is worth noting that all couples lost spousal time on weekdays - 45 to 75 minutes on an average weekday. Thus, no one fully escaped work demands impinging on spousal time. However, having children at home seems to have allowed married participants to resist increasing their weekday minutes of paid employment participation and even slightly disengage from paid employment. It may be that parents pulled back slightly from the labor force when faced with the necessity of finding someone to care for the children. Qualitative work has found that both wives and husbands in dual-earner families utilize strategies that allow them to invest less time in paid employment and more time in their families (Becker and Moen 1999). This study offers quantitative evidence of this process. As they pulled back from the work force, they were not only able to spend time with their children, but with each other.

Examining time-use strategies on weekend days showed that couples with children at home paid a social and personal cost for maintaining their levels of spousal time. Individuals with children at home maintained spousal time by cutting in half the amount of time they spent with friends and extended family. In other words, it seems that married individuals with children at home spent less time socializing with friends and extended family on weekend days. Although individuals without children at home also lost some social time, the reduction was not nearly as drastic. Married individuals with children at home also decreased their personal leisure time by 30 minutes, whereas their counterparts without children at home lost only 13 minutes of personal leisure.

Marriage and parenting have been called "greedy" institutions in that they demand as much time as possible from participants to the exclusion of engaging 
in other pursuits. This research is in line with others that find marriage often leads to less social participation (Gerstel and Sarkisian 2006). Other studies have noted declines in social participation and personal networks (McPherson, Smith-Lovin and Brashears 2006; Putnam 2000), and this finding shows that married couples with children cut back on spending time in their personal networks to meet the demands of parenting and married life.

This finding suggests, but cannot prove, that contemporary spouses with children value parenting and marital behavior over spending time with others and even having leisure time to themselves. That is, it seems that on weekends married couples with children would rather spend time with their children and their spouses than with friends, extended family or even by themselves. This finding demonstrates both the strength of the intensive parenting norm and the strength of the companionate marriage norm (Cherlin 2004; Coontz 2005). Because parents feel more rushed now than in the past on weekdays and have less time with their spouses, weekends may have become the main opportunity for family time or a chance to reconnect with immediate family members. Parents may willingly give up (or may feel obligated to give up) social activities with other adults and/or personal leisure time to experience "slowed-down" and "obligation-free" time on weekends with each other and their children (see Daly 2001).

This study is not without limitations, and most of the limitations relate to the data. Very few large-scale, time-diary studies collect data on both spouses. Although the TUESA 1975 data did, the ATUS 2003 did not. Consequently, like most studies of time diaries, this data suffers from single-reporter bias. Thus, the findings rely on how accurate and truthful the participant was in reporting time use on the survey day. Some studies that use other methods of evaluating time use, such as experience sampling method, show that when both spouses are given an opportunity to report on their activities, spouses' reports of doing activities together do not always agree (Larson and Richards 1994). Thus, these findings are limited because only one spouse was able to report whether they were with their spouse during an activity.

Another data limitation is that the two panels were cross-sectional, not longitudinal. Thus, this study only measures true change in spousal time to the extent that all of the variables that influence spousal time have been correctly identified and included in the model. Although most studies assessing changes in time allocation use the same technique (Bianchi et al. 2006; Robinson and Godbey 1999; Sayer 2005; Sayer et al. 2004), not controlling influential variables may still be a problem. Results need to be interpreted with this limitation in mind.

A third limitation is the issue of only having two time points. This forces a linear structure on the trends that may not reflect true historical change. That is, the drop in spouses' time may have been constant and linear, or it may have occurred suddenly. Knowing the shape of the decline might help identify the mechanisms behind the shift. At the very least, the identified linear trend should be interpreted cautiously. 
A final limitation is selection. Married-couples and married couples with children have become a more select group since 1975. The data showed that relative to single individuals, married individuals have become older and more educated (analysis not shown). The same findings exist for married individuals with children at home compared with single individuals who have children at home. These changes in married parents' characteristics may influence the relationship between having a child at home and spousal time. Older parents may be better able to control their time because older workers usually have more control over their work schedules. This may allow them to allocate time both to being with their children and being alone with their spouses. Thus, these findings have to be interpreted in light of the fact that having children at home is not necessarily exogenous to time allocation.

Despite these limitations, this study adds to knowledge about contemporary family change, especially change in married families with children at home. The findings from this study suggest a picture of parents who have responded to the intensive parenting norm, but who seem to be actively resisting declines in spousal time stemming from their parenting. Their strategies range from reducing paid employment demands on weekdays to spending less time with friends and relatives on weekend days. These findings are important because they show that although children require large investments of parental time, new social norms regarding parental investment have not overcome marital norms of spouses' companionship. Rather, the emotional intimacy of spousal companionship, and the time it takes to develop it (Kingston and Nock 1987; Wilcox and Nock 2006), remain an important component of contemporary marriage.

\section{Notes}

1. Because children may need different levels of parental-time inputs depending on their ages, I conducted an analysis that used the age of the youngest child to dummy code participants into "parenting life-cycle stages" (e.g., infants, toddlers, schoolaged children, adolescents, with non-parents as the comparison group). The findings using these dummy codes were similar to the findings presented in the manuscript. For example, the magnitude of the year by parent interaction was similar for all age groups. Consequently, I present the simpler treatment of children by only using the "children in the household" dummy variable and the "number of children" variable.

2. Although two other datasets exist that might have filled in the years between 1975 and 2003, neither dataset was used. Robinson and his colleagues collected timediary data in 1985 . However questions exist as to the comparability of the coding in this data, and the full dataset is not publicly available (Sayer 2001). The Family Interaction, Social Capital and Trends in Time Use was collected in 1998. Estimates produced using the 1998 data were not significantly different from the ATUS 2003 estimates (analysis not shown). Thus, this study only used the ATUS 2003.

3. The TUESA 1975 and the ATUS 2003 were collected by different research teams. However, it is unlikely that this influenced the findings. Both studies used nationally representative samples that were obtained using stratified random sampling. Both 
studies used standard time-use coding techniques based on Szalai's (1972) methods, and both used common time-diary collection techniques. Although the 1975 survey used face-to-face interviews and the 2003 survey used telephone interviews, both methods are comparable as long as interviewers assist participants in filling out the time diary and that participants only had to recall the previous day's events (Harvey 1993; Robinson and Godbey 1999). This was the case in both surveys. Further, findings from the ATUS 2003 are similar to the findings from the FISCT; the FISCT was conducted by members of the same research team that conduct the 1975 survey.

4. This analysis was restricted to married couples because of a lack of theory that addresses the importance of cohabiting partner interaction. Further, very few cohabiting parents participated in the 1975 study.

5. Although the increase in the amount of time that couples contribute to paid labor employment is largely due to wives' increased labor force participation, previous versions of this study showed that using changes in wives' vs. changes in husbands' hours did not explain spousal time declines (analysis not shown).

6. I ran separate analyses that used dummy variables to represent income quartiles or income quintiles instead of the continuous scales that are reported. These different specifications of income were never significant.

7. Because time allocation is by definition a zero-sum activity, any declines in spousal time in 2003 meant that individuals had increased time spent in other activities.

8. In the multivariate models, weekday and weekend day differences in spousal time were significant at the $\mathrm{p}<.001$ level even after holding constant the control variables (including minutes of work on the diary day).

9. About 27 percent of the total sample reported spending no time (e.g., 0 minutes) with a spouse on the diary day. A reviewer suggested that Tobit models should be run and compared with the OLS models. For the weekend day group, the Tobit model results were essentially the same as the OLS model (tobit models available upon request). For the weekday group, the Tobit model results were also the same as the OLS models with the exception that the children at home by year interaction was not significant. Although the interaction was positive, like the OLS result was, it did not attain statistical significance in the Tobit model. Interestingly, however, the OLS predicted spousal time values were much closer to the actual means than the Tobit model predictions. Further, the weekday decomposition components using OLS totaled a -53.92 - which was only half a point different than the actual weekday spousal time mean decline of -54.41 . Because the OLS models seem to get closest to the actual mean changes they are presented and discussed. However, the differences between the OLS and Tobit results should be noted.

\section{References}

Amato, Paul R., David R. Johnson, Alan Booth and Stacey J. Rogers. 2003. "Continuity and Change in Marital Quality Between 1980 and 2000." Journal of Marriage and Family 65(1):1-22.

Amato, Paul R., Alan Booth, David R. Johnson and Stacey J. Rogers. 2007. Alone Together: How Marriage in America is Changing. Harvard University Press.

Bachu, Amara, and Martin O'Connell. 2000. Fertility of American Women: June 1998. (No. P20-526, Current Population Reports). Washington, DC: U.S. Census Bureau. 
Becker, Penny E., and Phyllis Moen. 1999. "Scaling Back: Dual-Earner Couples' WorkFamily Strategies." Journal of Marriage and Family 61(4):995-1007.

Bianchi, Suzanne M. 2000. "Maternal Employment And Time With Children: Dramatic Change Or Surprising Continuity?” Demography 37(4):401-14.

Bianchi, Suzanne M., John P. Robinson and Melissa A. Milkie. 2006. Changing Rhythms of American Family Life. Russell Sage Foundation.

Bumpass, Larry L. 1982. "The changing linkage of nuptiality and fertility in the United States." Pp. 195-209. Nuptiality and Fertility. Lado T. Ruzicka, editor. Ordina Editions. Chadiha, Letha A., Joseph Veroff and Douglas Leber. 1998. "Newlywed's Narrative Themes: Meaning in the First Year of Marriage for African-American and White Couples." Journal of Comparative Family Studies 29(1):115-30.

Cherlin, Andrew J. 2004. "The Deinstitutionalization of American Marriage." Journal of Marriage and Family 66(4):848-61.

Coiro, Mary J., and Robert E. Emery. 1998. "Do Marriage Problems Affect Fathering More than Mothering? A Quantitative and Qualitative Review." Clinical Child and Family Psychology Review 1(1):23-40.

Coltrane, Scott. 1996. Family Man: Fatherhood, Housework, and Gender Equity. Oxford University Press.

Coontz, Stephanie. 2005. Marriage, a History. Viking Penguin.

Daly, Kerry J. 2001. "Deconstructing Family Time: From Ideology to Lived Experience." Journal of Marriage and Family 63(2):283-94.

Erel, Osnat, and Bonnie Burman. 1995. "Interrelatedness of Marital Relations and ParentChild Relations: A Meta-Analytic Review.” Psychological Bulletin 118(1):108-32.

Firebaugh, Glenn. 1997. Analyzing Repeated Surveys. Sage.

Gerstel, Naomi, and Natalia Sarkisian. 2006. "Marriage: The Good, the Bad, and the Greedy." Contexts 5(4):16-21.

Griswold, Robert L. 1997. "Generative Fathering: A Historical Perspective." Pp. 71 86. Generative Fathering: Beyond Deficit Perspectives. Alan J. Hawkins and David C. Dollahite, editors. Sage.

Harvey, Andrew S. 1993. "Guidelines for Time Use Collection." Social Indicators Research 30(2/3):197-228.

Hays, Sharon. 1996. The Cultural Contradictions of Motherhood. Yale University Press.

Jacobs, Jerry A., and Kathleen Gerson. 2004. The Time Divide: Work, Family, and Gender Inequality. Harvard University Press.

Juster, F. Thomas, and Frank P. Stafford. 1985. "Introduction and Overview." Pp. 1-17. Time, Goods, and Well-being. F. Thomas Juster and Frank P. Stafford, editors. University of Michigan Press.

Juster, F. Thomas, Greg J. Duncan, John P. Robinson and Frank P. Stafford. 2001. "Time Use in Economic and Social Accounts 1975-1976.” ICPSR version. Ann Arbor, MI: Survey Research Center [producer] and Inter-university Consortium for Political and Social Research [distributor].

Kingston, Paul W., and Steven L. Nock. 1987. "Time Together Among Dual-Earner Couples." American Sociological Review 52(3):391-400.

Lareau, Annette. 2002. "Invisible Inequality: Social Class and Childrearing in Black Families and White Families." American Sociological Review 67(5):747-76.

Larson, Reed, and Maryse Heather Richards. 1994. Divergent Realities. Basic Books. 
McPherson, Miller, Lynn Smith-Lovin and Matthew E. Brashears. 2006. "Social Isolation in America: Changes in Core Discussion Networks over Two Decades." American Sociological Review 71(3):353-75.

Milkie, Melissa A., Marybeth J. Mattingly, Kei M. Nomaguchi, Suzanne M. Bianchi and John P. Robinson. 2004. "The Time-Squeeze: Parental Statuses and Feelings about Time with Children." Journal of Marriage and Family 66(3):739-61.

Pleck, Elizabeth J., and Joseph H. Pleck. 1996. "Fatherhood Ideals in the United States: Historical Dimensions." Pp. 33-48. The Role of the Father in Child Development. Michael E. Lamb, editor. Wiley.

Presser, Harriet B. 2000. "Nonstandard Work Schedules and Marital Instability." Journal of Marriage and Family 62(1):93-110.

Putnam, Robert D. 2000. Bowling Alone: The Collapse and Revival of American Community. Simon \& Schuster.

Robinson, John P., and Geoff Godbey. 1999. Time for Life. Pennsylvania State University Press.

Roxburgh, Susan. 2006."I Wish We Had More Time to Spend Together...': The Distribution and Predictors of Perceived Family Time Pressures Among Married Men and Women in the Paid Labor Force." Journal of Family Issues 27(4):529-53.

Sandberg, John F., and Sandra L. Hofferth. 2001. "Changes in Children's Time With Parents: United States, 1981-1997.” Demography 38(3):423-36.

Sayer, Liana C. 2005. "Gender, Time and Inequality: Trends in Women's and Men's Paid Work, Unpaid Work and Free Time.” Social Forces 84(1):285-303.

. 2001. Time Use, Gender and Ineqaulity: Differences in Men's and Women's Market, Nonmarket, and Leisure Time. PhD Dissertation. University of Maryland. Available at: http://proquest.umi.com/pqdweb? index $=0 \& \mathrm{did}=726113091 \&$ SrchMode $=2 \&$ si $\mathrm{d}=2 \& \mathrm{Fmt}=6 \& \mathrm{VInst}=\mathrm{PROD} \& \mathrm{VType}=\mathrm{PQD} \& \mathrm{RQT}=309 \& \mathrm{VName}=\mathrm{PQD} \& \mathrm{TS}=12$ $56227252 \&$ clientId $=1652$.

Sayer, Liana C., Suzanne M. Bianchi and John P. Robinson. 2004. "Are Parents Investing Less in Children? Trends in Mothers' and Fathers' Time with Children." American Journal of Sociology 110(1):1-43.

Simon, Robin W. 1995. "Gender, Multiple Roles, Role Meaning, and Mental Health." Journal of Health and Social Behavior 36(2):182-94.

Stearns, Peter N. 2003. Anxious Parents: A History of Modern Childrearing in America. New York University Press.

Stinson, Linda L. 1999. "Measuring how people spend their time: a time-use survey design.” Monthly Labor Review 122(8):12-19.

Szalai, Alexander. 1972. The Use of Time: Daily Activities of Urban and Suburban Populations in Twelve Countries. The Hague: Mouton.

Ventura, Stephanie J., Joyce C. Abma, William D. Mosher and Stanley Henshaw. 2004. Estimated Pregnancy Rates for the United States, 1990-2000: An update. Available at: http://www.cdc.gov/nchs/data/nvsr/nvsr52/nvsr52_23.pdf.

White, Lynn. 1983. "Determinants of Spousal Interaction: Marital Structure or Marital Happiness?" Journal of Marriage and the Family 45(3):511-19.

Wilcox, W. Bradford, and Steven L. Nock. 2006. "What's Love Got To Do With It? Equality, Equity, Commitment and Women's Marital Quality." Social Forces 84(3):1321-45.

Zelizer, Viviana A. 1994. Pricing the Priceless Child. Princeton University Press. 